\title{
Association Between a Polymorphism (rs2071214) in Baculoviral IAP Repeat Containing 5 Gene (BIRC5) and Ischemic Stroke in Korean Population
}

\author{
Jinmann Chon, $\mathrm{MD}^{1}$, Hee-Sang Kim, $\mathrm{MD}^{1}$, Dong Hwan Yun, $\mathrm{MD}^{1}$, Seung Don Yoo, $\mathrm{MD}^{1}$, \\ Dong Hwan Kim, $\mathrm{MD}^{1}$, Seung Ah Lee, $\mathrm{MD}^{1}$, Su Kang Kim, $\mathrm{MD}^{2}$, Hae Jeong Park, $\mathrm{MD}^{2}$, \\ Joo-Ho Chung, $\mathrm{MD}^{2}$, Sungjoon Chung, $\mathrm{MD}^{1}$, Jinah Yeo, $\mathrm{MD}^{1}$
}

\begin{abstract}
${ }^{1}$ Department of Physical Medicine and Rehabilitation, Kyung Hee University School of Medicine, Seoul;
${ }^{2}$ Kohwang Medical Research Institute, Kyung Hee University, Seoul, Korea
\end{abstract}

\begin{abstract}
Objective To investigate whether baculoviral inhibitor of apoptosis (IAP) repeat containing 5 gene (BIRC5) polymorphisms are associated with the development and clinical phenotypes of ischemic stroke in Korea population. Methods We enrolled 121 ischemic stroke patients and 291 control subjects. Ischemic stroke patients were divided into subgroups according to the scores of National Institutes of Health Stroke Survey $(<6$ or $\geq 6)$ and Modified Barthel Index ( $<60$ or $\geq 60$ ). Single nucleotide polymorphisms (SNPs) of BIRC5 (rs3764383 and rs2071214) were selected and genotyped by direct sequencing for all subjects. Multiple logistic regression models (codominant 1 and 2, dominant, recessive, overdominant and log-additive) were used to estimate odds ratios (ORs), 95\% confidence intervals (CIs), and p-values.

Results In analysis of stroke susceptibility, the genotype and allele frequencies of rs3764383 exhibited no difference between the control group and the ischemic stroke group. SNP rs2071214 was associated with ischemic stroke in the codominant ( $\mathrm{p}=0.003)$, dominant $(\mathrm{p}=0.002)$, overdominant $(\mathrm{p}=0.005)$, and log-additive $(\mathrm{p}=0.008)$ models, respectively. The $\mathrm{G}$ allele frequency of $\mathrm{rs} 2071214$ was significantly $(\mathrm{p}=0.009)$ associated with susceptibility for ischemic stroke (OR, 1.57; 95\% CI, 1.12-2.21). However, in the analysis for clinical phenotype, no SNP of the BIRC5 gene was found to be associated with ischemic stroke.

Conclusion These results suggest that a missense SNP (rs2071214) of BIRC5 may be associated with the development of ischemic stroke in the Korean population.
\end{abstract}

Keywords Brain infarction, BIRC5 protein, Single nucleotide polymorphism

Received June 15, 2015; Accepted September 21, 2015

Corresponding author: Jinah Yeo

Department of Physical Medicine and Rehabilitation, Kyung Hee University Medical Center, 23 Kyungheedae-ro, Dongdaemun-gu, Seoul 02447, Korea. Tel: +82-2-958-8565, Fax: +82-2-958-8560, E-mail: especially02@hanmail.net

ORCID: Seung Don Yoo (http://orcid.org/0000-0003-4513-2560); Seung Ah Lee (http://orcid.org/0000-0002-3426-6259); Jinah Yeo (http://orcid. org/0000-0003-2796-0805).

() This is an open-access article distributed under the terms of the Creative Commons Attribution Non-Commercial License (http://creativecommons.org/ licenses/by-nc/4.0) which permits unrestricted noncommercial use, distribution, and reproduction in any medium, provided the original work is properly cited. Copyright $\odot 2016$ by Korean Academy of Rehabilitation Medicine 


\section{INTRODUCTION}

Stroke is an acute neurological emergency that can result in long-term disability. It is the second most common cause of death in Korea [1]. Stroke is generally classified as either ischemic stroke or hemorrhagic stroke. Several environmental factors are associated with increased risk of stroke. Several lines of evidences have indicated that genetic factors are also involved in the development of stroke [2-4]. Numerous genetic studies have reported the relationships between stroke and single nucleotide polymorphisms (SNPs) of genes such as methylenetetrahydrofolate reductase (MTHFR) [5], tumor protein p53 (Tp53) [6], transforming growth factor beta 1 (TGFB1) [7], gap junction protein alpha 4 (GJA4, also known as connexin 37) [8], and interleukin 10 (IL10) [9].

Apoptosis or programmed cell death involves complex signaling pathways and cascades of molecular events. Normal growth and development of organisms require maintenance of a dynamic balance between systems that promote cell survival and those that induce apoptosis. Intracellular proteases called caspases can degrade cellular contents by proteolysis upon activation of the death pathway.

Baculoviral inhibitor of apoptosis (IAP) repeat containing 5 gene (BIRC5) (located in 17q25) is a member of the IAP gene family. This gene encodes for surviving that can inhibit caspase activation, thereby leading to negative regulation of apoptosis or programmed cell death. In mouse model of stroke, survivin expression by cerebrovascular endothelium is upregulated [10]. It is particularly found in the microvasculature within the infarct and peri-infarct areas [10].

Recent studies have shown that apoptotic neuronal death is delayed in the surrounding area of necrotic core, leading to the propagation of brain damage $[11,12]$. Many studies have suggested that apoptosis, necrosis, and oxidative stress may lead to the development of ischemic cascade. We hypothesized that survivin was associated with ischemic stroke. Therefore, we evaluated whether SNPs of the BIRC5 gene were associated with the genetic susceptibility and clinical phenotypes of ischemic stroke in the Korean population.

\section{MATERIALS AND METHODS}

\section{Subjects}

Subjects for this investigation were 121 ischemic stroke patients who visited the Stroke Center at Kyung Hee University and the emergency room of Kyung Hee Hospital between October 2007 and April 2011 with onset between 1 week and 1 month. Patients with hemorrhagic stroke, trauma, hematoma, brain tumors, and accidental or iatrogenic stroke were excluded from this study. All patients were diagnosed using cranial computed tomography, magnetic resonance imaging, angiography, or duplex sonography. Controls ( $\mathrm{n}=291)$ were selected from healthy subjects who were examined during health check-up. None of them had any clinical evidence of stroke. Vascular risk factors (smoking, alcohol intake, diabetes mellitus, hypertension, hyperlipidemia) were evaluated for all subjects. All ischemic stroke patients were classified into two clinical subgroups according to the respective results of the National Institutes of Health Stroke Survey (NIHSS) and Modified Barthel Index (MBI). In a previous study, patients with MBI score higher than 60 required shorter time of stay at home [13]. In this study, MBI score of 60 appeared to be a reference point for patients who were dependent or independent requiring only partial assist [13]. In terms of NIHSS score, score below 6 has been found to be able to predict good outcome in a study consisting of 1,281 stroke patients [14]. Therefore, we classified stroke patients into clinical phenotypes according to the NIHSS score of $6(<6$ or $\geq 6)$ and the MBI score of 60 $(<60$ or $\geq 60)$.

Written informed consent was obtained from all subjects. If patients were unable to communicate, consent was obtained from their guardians or close relatives. This study was approved by the Ethics Review Committee of the Medical Research Institute, Kyung Hee University College of Medicine.

\section{SNP selection and genotyping}

Although many studies have explored the potential association between several SNPs (including rs9904341, rs17878467, rs2071214, and rs8073069) in survivin gene and the susceptibility to various tumors [15], the associations between these SNPs and the susceptibility to stroke are not well explored. After searching the dbSNP database (http://www.ncbi.nlm.nih.gov/SNP/), we selected 
the following two SNPs: $-1547 \mathrm{~A} / \mathrm{G}$ (rs3764383) located in the promoter region and $+9194 \mathrm{~A} / \mathrm{G}$ (rs2071214) located in exon4 (Fig. 1) that had greater than 0.1 heterozygosity among SNPs of the BIRC5 gene for this study.

Peripheral blood sample was collected from each subject for DNA extraction. Genomic DNA was extracted using QIAamp DNA mini kit (QIAGEN, Valencia, CA, USA). Genotypes were determined by direct sequencing (MACROGEN, Seoul, Korea). Polymerase chain reactions (PCRs) were performed with the following primers: for rs3764383 (sense, 5'-TGCCTATAATCCCAGCTACTCA-3'; antisense, 5' -CCAGAGAAGTCACTCCCACATT-3'; product size, $383 \mathrm{bp}$ ) and for rs2071214 (sense, 5' -TCACCAGAGCACGAAAGAATTA-3'; antisense, 5' -GGCTTCTGCTGTAGTTCAACCT-3'; product size, $423 \mathrm{bp}$ ). PCR products were sequenced using an ABI PRISM 3730XL analyzer (PE Applied Biosystems, Foster City, CA, USA). SeqMan II software (DNASTAR Inc., Madison, WI, USA) was used to analyze the sequencing data.

Sequence data were evaluated using SNPStats (http:// bioinfo.iconcologia.net/index.php?module=Snpstats), SNPAnalyzer (ISTECH Inc., Goyang, Korea), and HelixTree (Golden Helix Inc., Bozeman, MT, USA). HardyWeinberg equilibrium (HWE) was calculated using chisquare test. Logistic regression models (codominant, dominant, and recessive) were used to determine the odds ratios (ORs), 95\% confidence intervals (CIs), and pvalues. The required sample size for statistical power was estimated using a genetic power calculator (http://pngu. mgh.harvard.edu/ purcell/gpc/cc2.html). The significance level for all statistical tests was set at $\mathrm{p}<0.05$.

\section{Statistical analysis}

Chi-square test and Student t-test were used to compare baseline characteristics between the ischemic stroke group and the control group. SPSS ver. 12.0 (SPSS Inc., Chicago, IL, USA) was used as the statistical program and statistical significance was at $\mathrm{p}<0.05$. To analyzed the genetic association between BIRC5 polymorphisms and ischemic stroke, multiple logistic regression analyses with adjustment for age and gender were performed using the following: codominant 1 (major allele homozygotes vs. heterozygotes), codominant 2 (major allele homozygotes vs. minor allele homozygotes), dominant (major allele homozygotes vs. heterozygotes+minor allele homozygotes), recessive (major allele homozygotes+heterozygotes vs. minor allele homozygotes), and log-additive (major allele homozygotes vs. heterozygotes vs. minor allele homozygotes).

In the codominant model, every genotype can gives a different and non-additive risk. Therefore, we compared the major allele homozygotes (the most frequent alleles) to heterozygotes in codominant 1 and minor allele homozygotes in codominant 2 . In the dominant model, a single copy of allele was enough to modify the risk with heterozygous and homozygous genotypes having the same risk. In the recessive model, two copies of allele were necessary to change the risk. In the overdominant model, heterozygotes were compared to both allele homozygotes. In the log additive model, each copy of allele modified the risk in an additive form.

\section{RESULTS}

\section{Subjects}

The patient population consisted of 121 (67 males and 54 females) ischemic stroke patients. There were 291 (152 males and 139 females) healthy blood donors who visited the center for regular health check-ups. The mean age of the stroke group was $65.74 \pm 12.12$ (mean \pm standard deviation) years. The mean age of the control group was $63.04 \pm 9.36$ years. Stroke patients were divided according to NIHSS (scores of 13 neurological symptoms; $<6$ or $\geq 6$ ) or MBI (scores of 10 activities of general life; $<60$ or $\geq 60$ ). The number of ischemic stroke patients with NIHSS scores of $<6$ and $\geq 6$ were 56 and 57 , respectively. The number of ischemic stroke patients with MBI scores of $<60$ and $\geq 60$ were 71 and 25 , respectively. The clini-

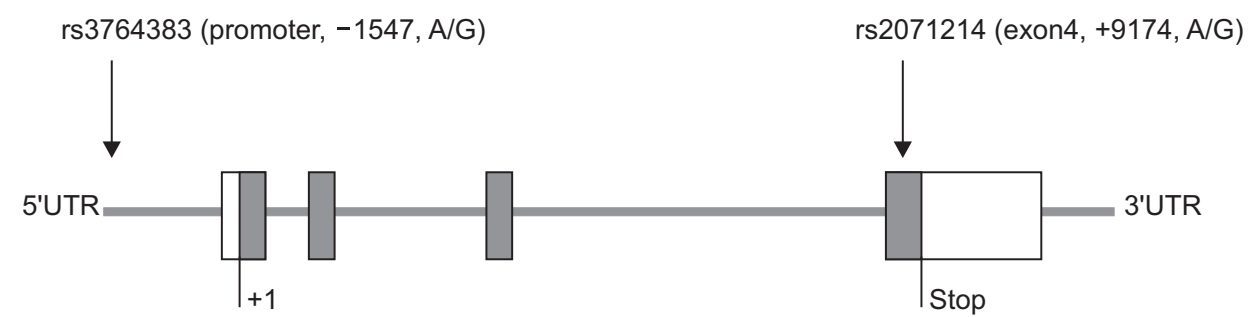

Fig. 1. Selected two single nucleotide polymorphisms (SNPs) of BIRC5: rs3764383 and rs2071214. 
cal characteristics of patients with ischemic stroke and control subjects are summarized in Table 1 . There was no significant difference in sex, age, or vascular risk factors between the two groups.

Table 1. Characteristics of ischemic stroke patients and control subjects

\begin{tabular}{lccc}
\hline & $\begin{array}{c}\text { Stroke } \\
(\mathbf{n = 1 2 1})\end{array}$ & $\begin{array}{c}\text { Control } \\
(\mathbf{n = 2 9 1})\end{array}$ & p-value \\
\hline Male & $67(55.3)$ & $152(52.2)$ & 0.42 \\
Age (yr) & $65.74 \pm 12.12$ & $63.04 \pm 9.36$ & 0.44 \\
Vascular risk factors (\%) & & & \\
Smoking & 40.5 & 37.6 & 0.48 \\
Alcohol & 32.6 & 30.3 & 0.49 \\
Diabetes mellitus & 14.5 & 12.2 & 0.49 \\
\hline Hypertension & 45.1 & 43.3 & 0.51 \\
\hline Hyperlipidemia & 30.4 & 26.7 & 0.45 \\
\hline
\end{tabular}

Values are presented as number (\%) or mean \pm standard deviation.

\section{Analysis of susceptibility}

The genotype and allele frequencies of the two SNPs are listed in Table 2. Two SNPs (rs3764383, rs2071214) of the BIRC5 gene were in HWE in the ischemic stroke group and the control group. For rs3764383, the frequencies of AA, AG, and GG genotypes in the control group were $63.2 \%, 29.6 \%$, and $7.2 \%$, respectively. Its frequencies of AA, AG, and GG genotypes in the ischemic stroke group were $56.2 \%, 39.7 \%$, and $4.1 \%$, respectively. Allele frequencies of $A$ and $G$ in the control group were $78.0 \%$ and $22.0 \%$, respectively. The allele frequencies of $A$ and $G$ in the ischemic stroke group were $76.0 \%$ and $24.0 \%$, respectively. No correlation was observed between rs3764383 SNP and susceptibility to ischemic stroke. The frequencies of the AA, AG, and GG genotypes for rs2071214 in the control group were $63.5 \%, 30.0 \%$, and $6.5 \%$, respectively, and $47.9 \%, 43.8 \%$, and $8.3 \%$, respectively, in the ischemic stroke group, respectively. The missense SNP rs2071214 was associated with ischemic stroke in the codominant $(\mathrm{p}=0.003)$, dominant $(\mathrm{p}=0.002)$, overdominant $(\mathrm{p}=0.005)$, and log-additive $(\mathrm{p}=0.008)$ models, respectively. The $\mathrm{G}$

Table 2. Genotype and allele frequencies of BIRC5 polymorphisms (rs3764383 and rs2071214) in ischemic stroke patients

\begin{tabular}{|c|c|c|c|c|c|c|}
\hline SNP & Type & Control & Stroke & Model & OR (95\% CI) & p-value \\
\hline \multirow[t]{8}{*}{ rs3764383 } & $\mathrm{A} / \mathrm{A}$ & $184(63.2)$ & $68(56.2)$ & Codominantl & $1.54(0.98-2.42)$ & 0.064 \\
\hline & $\mathrm{A} / \mathrm{G}$ & $86(29.6)$ & $48(39.7)$ & Codominant2 & $0.69(0.25-1.90)$ & 0.47 \\
\hline & $\mathrm{G} / \mathrm{G}$ & $21(7.2)$ & $5(4.1)$ & Dominant & $1.37(0.89-2.12)$ & 0.15 \\
\hline & & & & Recessive & $0.59(0.21-1.60)$ & 0.28 \\
\hline & & & & Overdominant & $1.55(1.01-2.45)$ & 0.054 \\
\hline & & & & Log-additive & $1.14(0.80-1.61)$ & 0.47 \\
\hline & A & $454(78.0)$ & $184(76.0)$ & & 1 & \\
\hline & G & $128(22.0)$ & $58(24.0)$ & & $1.12(0.78-1.59)$ & 0.37 \\
\hline \multirow[t]{8}{*}{ rs2071214 } & $\mathrm{A} / \mathrm{A}$ & $184(63.5)$ & $58(47.9)$ & Codominantl & $2.02(1.28-3.19)$ & $0.003^{*}$ \\
\hline & $\mathrm{A} / \mathrm{G}$ & $87(30.0)$ & $53(43.8)$ & Codominant2 & $1.72(0.75-3.95)$ & 0.201 \\
\hline & $\mathrm{G} / \mathrm{G}$ & $19(6.5)$ & $10(8.3)$ & Dominant & $1.96(1.27-3.03)$ & $0.0023^{*}$ \\
\hline & & & & Recessive & $1.30(0.58-2.91)$ & 0.52 \\
\hline & & & & Overdominant & $1.89(1.21-2.95)$ & $0.0051^{*}$ \\
\hline & & & & Log-additive & $1.57(1.12-2.20)$ & $0.0084^{*}$ \\
\hline & A & $457(78.4)$ & $169(69.8)$ & & 1 & \\
\hline & G & $125(21.6)$ & $73(30.2)$ & & $1.57(1.12-2.21)$ & $0.009^{*}$ \\
\hline
\end{tabular}

Values are presented as number (\%).

SNP, single nucleotide polymorphism; BIRC5, baculoviral inhibitor of apoptosis repeat containing 5; OR, odd ratio; CI, confidence interval.

${ }^{*} \mathrm{p}<0.05$ by logistic regression analysis with the codominant, dominant, and recessive models after controlling age and gender as covariates. 
allele frequency of rs2071214 was significantly ( $p=0.009)$ higher in the ischemic stroke group than that in the control group (21.6\% vs. 30.2\%; OR, 1.57; 95\% CI, 1.12-2.21). These data suggested that the rs2071214 SNP of the BIRC5 gene might be associated with ischemic stroke and that the $\mathrm{G}$ allele of rs2071214 might be a risk factor for the development of ischemic stroke.

\section{Analysis of clinical phenotypes}

In analysis of NIHSS (Table 3), the frequencies of AA, AG, and GG genotypes for rs3764383 in the NIHSS $<6$ group were $57.1 \%, 41.1 \%$, and $1.8 \%$, respectively, and $52.6 \%, 40.4 \%$, and $7.0 \%$, respectively, in the NIHSS $\geq 6$ group. The genotype and allele frequencies of rs3764383 were not significantly $(p>0.05)$ different between the NIHSS $<6$ group and the NIHSS $\geq 6$ group. The rs3764383 was not significantly $(\mathrm{p}>0.05)$ associated with NIHSS scores in the codominant model (OR, 1.06; 95\% CI, 0.49-2.28; $\mathrm{p}=0.88$ ), the dominant model (OR, 1.19; 95\% CI, 0.57$2.51 ; \mathrm{p}=0.64)$, the recessive model (OR, 4.06; 95\% CI, 0.44-37.70; $\mathrm{p}=0.17$ ), the overdominant model (OR, 0.97; 95\% CI, 0.46-2.06; $\mathrm{p}=0.93$ ), or the log-additive model (OR, 1.33; 95\% CI, 0.71-2.38; $\mathrm{p}=0.4$ ). For rs2071214, the fre- quencies of the AA, AG, and GG genotypes were $46.4 \%$, $44.6 \%$, and $8.9 \%$, respectively, in the NIHSS $<6$ group, and $49.1 \%, 43.945$, and $7.0 \%$, respectively, in the NIHSS $\geq 6$ group. The genotype and allele frequencies of rs2071214 were not significantly $(p>0.05)$ different between the NIHSS $<6$ group and NIHSS $\geq 6$ group. The rs2071214 was not significantly ( $>0.05)$ associated with NIHSS scores in the codominant model (OR, 0.93; 95\% CI, 0.43-2.03; $\mathrm{p}=0.86$ ), the dominant model (OR, 0.90; 95\% CI, 0.43-1.90; $\mathrm{p}=0.79$ ), the recessive model (OR, 0.76; 95\% CI, 0.19-3.05; $\mathrm{p}=0.7$ ), the overdominant model (OR, 0.98; 95\% CI, 0.462.06; $\mathrm{p}=0.95)$, or the log-additive model (OR, $0.89 ; 95 \%$ CI, 0.49-1.61; $\mathrm{p}=0.7$ ).

Analysis results of MBI are shown in Table 4, the frequencies of the AA, AG, and GG genotypes for rs3764383 were $57.8 \%, 36.6 \%$, and $5.6 \%$, respectively in the $\mathrm{MBI}<60$ group, and $56.0 \%, 44.0 \%$, and $0.0 \%$, respectively, in the $\mathrm{MBI} \geq 60$ group. The genotype and allele frequencies of rs3764383 were not significantly ( $p>0.05$ ) different between the $\mathrm{MBI}<60$ group and the $\mathrm{MBI} \geq 60$ group. The rs3764383 was not significantly ( $p>0.05$ ) associated with MBI scores in the codominant model (OR, 1.30; 95\% CI, $0.48-3.50 ; \mathrm{p}=0.61)$, the dominant model (OR, 1.14; $95 \%$

Table 3. Multiple logistic regression analysis of BIRC5 polymorphisms (rs3764383 and rs2071214) in ischemic stroke patients with NIHSS scores

\begin{tabular}{|c|c|c|c|c|c|c|}
\hline SNP & Type & NIHSS $<6$ & NIHSS $\geq 6$ & Model & OR (95\% CI) & p-value \\
\hline \multirow[t]{8}{*}{ rs3764383 } & $\mathrm{A} / \mathrm{A}$ & $32(57.1)$ & $30(52.6)$ & Codominantl & $1.06(0.49-2.28)$ & 0.88 \\
\hline & $\mathrm{A} / \mathrm{G}$ & $23(41.1)$ & $23(40.4)$ & Codominant2 & $4.16(0.44-39.53)$ & 0.22 \\
\hline & $\mathrm{G} / \mathrm{G}$ & $1(1.8)$ & $4(7.0)$ & Dominant & $1.19(0.57-2.51)$ & 0.64 \\
\hline & & & & Recessive & $4.06(0.44-37.70)$ & 0.17 \\
\hline & & & & Overdominant & $0.97(0.46-2.06)$ & 0.93 \\
\hline & & & & Log-additive & $1.33(0.70-2.52)$ & 0.39 \\
\hline & A & $87(77.7)$ & $83(72.8)$ & & 1 & \\
\hline & G & $25(22.3)$ & $31(27.2)$ & & $1.30(0.71-2.38)$ & 0.40 \\
\hline \multirow[t]{8}{*}{ rs2071214 } & $\mathrm{A} / \mathrm{A}$ & $26(46.4)$ & $28(49.1)$ & Codominantl & $0.93(0.43-2.03)$ & 0.86 \\
\hline & A/G & $25(44.6)$ & $25(43.9)$ & Codominant2 & $0.74(0.17-3.11)$ & 0.68 \\
\hline & $\mathrm{G} / \mathrm{G}$ & $5(8.9)$ & $4(7.0)$ & Dominant & $0.90(0.43-1.90)$ & 0.79 \\
\hline & & & & Recessive & $0.76(0.19-3.05)$ & 0.70 \\
\hline & & & & Overdominant & $0.98(0.46-2.06)$ & 0.95 \\
\hline & & & & Log-additive & $0.89(0.49-1.61)$ & 0.70 \\
\hline & A & $77(68.8)$ & $81(71.1)$ & & 1 & \\
\hline & G & $35(31.3)$ & $33(28.9)$ & & $0.90(0.51-1.58)$ & 0.71 \\
\hline
\end{tabular}

Values are presented as number (\%).

BIRC5, baculoviral inhibitor of apoptosis repeat containing 5; SNP, single nucleotide polymorphism; NIHSS, National Institutes of Health Stroke Scale; OR, odds ratio; CI, confidence interval. 
CI, 0.43-3.02; $\mathrm{p}=0.8$ ), the recessive model (OR, 0.00; 95\% CI, 0.00-NA; $\mathrm{p}=0.16$ ), the overdominant model (OR, 1.41; 95\% CI, 0.52-3.78; $\mathrm{p}=0.5$ ), or the log-additive model (OR, 0.94; 95\% CI, 0.40-2.22; p=0.89). For rs2071214, the frequencies of the AA, AG, and GG genotypes were $45.1 \%$, $45.1 \%$, and $9.9 \%$, respectively, in the $\mathrm{MBI}<60$ group, and $52.0 \%, 40.0 \%$, and $8.0 \%$, respectively, in the $\mathrm{MBI} \geq 60$ group. The genotype and allele frequencies of rs2071214 were not significantly ( $p>0.05)$ different between the $\mathrm{MBI}<60$ group and the $\mathrm{MBI} \geq 60$ group. The rs2071214 was not significantly ( $\mathrm{p}>0.05)$ associated with MBI scores in the codominant model (OR, 0.80; 95\% CI, 0.29-2.22; $\mathrm{p}=0.67$ ), the dominant model (OR, 0.83; 95\% CI, 0.31-2.19; $\mathrm{p}=0.7$ ), the recessive model (OR, 1.08; 95\% CI, 0.18-6.44; $\mathrm{p}=0.93$ ), the overdominant model (OR, 0.81; 95\% CI, $0.30-2.15 ; \mathrm{p}=0.67$ ), or the log-additive model (OR, 0.90; 95\% CI, 0.41-1.96; $\mathrm{p}=0.79$ ). Consequently, the BIRC5 gene polymorphisms (rs3764383 and rs2071214) were not statistically associated with NIHSS scores $(<6$ or $\geq 6)$ or MBI scores $(<60$ or $\geq 60)$.

\section{DISCUSSION}

Stroke is a multifactorial disease caused by the interactions between several genetic factors and environmental factors. Recently, the importance of genetic factors in stroke has been demonstrated. It has been reported that protein kinase $\mathrm{C}$ eta $(P R K C H)$, apelin receptor (AGTRL1), and Rho guanine nucleotide exchange factor $10(A R-$ HGEF10) are three novel candidate genes for ischemic stroke in Japan $[16,17]$. In addition, chromosome 4q25 variants (rs2200733, rs10033464, and rs1906591) have been associated with the risk of ischemic stroke. Recent meta-analysis results on the risk effect of chromosome $4 \mathrm{q} 25$ variants on ischemic stroke have demonstrated that SNPs (rs2200733, rs1003346, and rs1906591) on chromosome $4 \mathrm{q} 25$ are associated with ischemic stroke risk, particularly cardioembolic stroke $[18,19]$.

Development of stroke is associated with multiple complex interactions such as excitotoxicity, acidotoxicity, ionic imbalance, oxidative stress, inflammation, and apoptosis [20]. Traditionally, neuronal death after cerebral ischemia has been considered entirely as necrotic in nature. However, research over the past decade has

Table 4. Multiple logistic regression analysis of BIRC5 polymorphisms (rs3764383 and rs2071214) in ischemic stroke patients with MBI scores

\begin{tabular}{|c|c|c|c|c|c|c|}
\hline SNP & Type & $\mathbf{M B I}<60$ & $\mathrm{MBI} \geq 60$ & Model & OR $(95 \%$ CI $)$ & p-value \\
\hline \multirow[t]{8}{*}{ rs3764383 } & $\mathrm{A} / \mathrm{A}$ & $41(57.8)$ & $14(56.0)$ & Codominantl & $1.30(0.48-3.50)$ & 0.61 \\
\hline & $\mathrm{A} / \mathrm{G}$ & $26(36.6)$ & $11(44.0)$ & Codominant2 & $0.00(0.00-\mathrm{NA})$ & \\
\hline & $\mathrm{G} / \mathrm{G}$ & $4(5.6)$ & $0(0.0)$ & Dominant & $1.14(0.43-3.02)$ & 0.80 \\
\hline & & & & Recessive & $0.00(0.00-\mathrm{NA})$ & 0.16 \\
\hline & & & & Overdominant & $1.41(0.52-3.78)$ & 0.5 \\
\hline & & & & Log-additive & $0.94(0.40-2.22)$ & 0.89 \\
\hline & A & $108(76.1)$ & $39(78.0)$ & & 1 & \\
\hline & G & 34 (23.9) & $11(22.0)$ & & $0.90(0.41-1.94)$ & 0.78 \\
\hline \multirow[t]{8}{*}{ rs2071214 } & $\mathrm{A} / \mathrm{A}$ & $32(45.1)$ & $13(52.0)$ & Codominantl & $0.80(0.29-2.22)$ & 0.67 \\
\hline & $\mathrm{A} / \mathrm{G}$ & $32(45.1)$ & $10(40.0)$ & Codominant2 & $0.97(0.15-6.16)$ & 0.98 \\
\hline & $\mathrm{G} / \mathrm{G}$ & $7(9.9)$ & $2(8.0)$ & Dominant & $0.83(0.31-2.19)$ & 0.70 \\
\hline & & & & Recessive & $1.08(0.18-6.44)$ & 0.93 \\
\hline & & & & Overdominant & $0.81(0.30-2.15)$ & 0.67 \\
\hline & & & & Log-additive & $0.90(0.41-1.96)$ & 0.79 \\
\hline & A & $96(67.6)$ & $36(72.0)$ & & 1 & \\
\hline & G & $46(32.4)$ & $14(28.0)$ & & $0.81(0.40-1.65)$ & 0.57 \\
\hline
\end{tabular}

Values are presented as number (\%).

BIRC5, baculoviral inhibitor of apoptosis repeat containing 5; SNP, single nucleotide polymorphism; MBI, Modified Barthel Index; OR, odds ratio; CI, confidence interval; NA, not applicable. 
revealed that many neurons in the ischemic area will undergo apoptosis after stroke [21]. Cerebral ischemia generally triggers the following two pathways of apoptosis: 1) the intrinsic pathway originating from mitochondrial release of cytochrome $\mathrm{c}$ that is associated stimulation of caspase-3, and 2) the extrinsic pathway originating from the activation of cell surface death receptors that results in the stimulation of caspase-8 $[11,22]$.

The BIRC5 gene (located in 17q25) is a member of the IAP family. This gene encodes for surviving that inhibits caspase activation, thereby leading to inhibition of apoptosis $[23,24]$. In rat model, increased level of survivin has been found in microvasculature after cerebral ischemia, suggesting that this protein may play a critical in ischemic stroke with important biological and therapeutic implications [10].

It is well-known that gene expression can be influenced by a SNP located within the promoter and/or other regulatory regions of the gene. Therefore, polymorphisms of survivin gene may have a functional consequence. It may affect the production or activity of survivin, thus regulating the susceptibility and clinical severity of ischemic stroke.

Our data revealed that a missense SNP (rs2071214) of BIRC5 was associated with the development of ischemic stroke in the codominant $(\mathrm{p}=0.003)$, the dominant $(\mathrm{p}=0.002)$, the overdominant $(\mathrm{p}=0.005)$, and the logadditive ( $\mathrm{p}=0.008)$ models in the Korean population. The $\mathrm{G}$ allele frequency of rs2071214 in the ischemic stroke group was significantly ( $\mathrm{p}=0.009$ ) higher than that in the control group (30.2\% vs. $21.6 \%$; OR, 1.57 ; $95 \%$ CI, $1.12-$ 2.21). The genotype and allele frequencies of rs3764383 showed no significant differences between the ischemic stroke patient group and the control group. There was no significant association between the survivin SNPs and the clinical phenotypes of ischemic stroke.

It has been demonstrated that the -1547 AA genotype of rs3764383 located in promoter region has a significantly younger age in ovarian cancer onset (58.8 vs. 70.1 years; $\mathrm{p}=0.001$ ) compared to patients with the -1547 GG genotype [25]. The survivin rs3764383 has been reported to be significantly associated with a worse prognosis of nonsmall cell lung cancer patients (AG/GG vs. AA; hazard ratio, 0.78; 95\% CI, 0.62-0.99) [26]. The promoter region may modify the transcription of survivin. Therefore, subjects carrying a genotype with higher expression of survivin may have decreased apoptotic activity to remove cells with DNA damage [26]. They might have a shorter survival time and poorer prognosis [26]. On the other hand, the survivin rs2071214 located in exon4 is a more common risk factor of tumor in Asians [15]. Survivin rs2071214 can result in amino acid change from Lys to GLu at codon 129 in exon 4. CREB-binding protein dependent acetylation on lysine 129 can promote nuclear accumulation of survivin. Acetylation at lysine 129 of survivin can lead to its homodimerization, while deacetylation can promote the formation of survivin monomers that heterodimerize with CRM1 and accelerate its nuclear export. Oncogenic transcription factor STAT3 is a binding protein of nuclear survivin. Acetylated survivin can bind to STAT3 and repress oncogenic transcription factor STAT3 transactivation of target gene promoters [27-29]. Wang et al. [29] have identified that rs2071214 $(A \rightarrow G)$ in a neuroblastoma cell line has defects in survivin nuclear localization. In vascular endothelial cells, survivin is upregulated in response to the release of angiogenic growth factors, including VEGF and Ang-1 [10].

It has been well-established that estrogens can protect neuronal death in animal models of cerebral ischemia. In animals subjected to ischemia, acute postischemic estradiol can further enhance the activation and nuclear translocation of STAT3 and STAT3-dependent transcription of target genes [30]. Recent study has demonstrated that survivin is a target gene of STAT3 in estradiol neuroprotection as evidenced by the ability of shRNA of survivin to reverse neuroprotection in ischemia [30]. Several polymorphisms have been described in the survivin gene. A recent study has demonstrated that rs 17878467 polymorphism of survivin gene is associated with a lower risk of hemorrhagic transformation in patients with ischemic stroke [31]. The biologic role of amino acid alterations associated with SNPs in ischemic stroke remains unclear. Nuclear localization of survivin may play a critical role in stroke susceptibility by modifying ischemic apoptosis, altering familiarity to angiogenic growth factor including VEGF and Ang-1, and inhibiting or activating different excitatory enzymes as in tumor.

The present study has several limitations. First, it is unclear which genetic polymorphisms can predict clinical phenotypes and prognosis of ischemic stroke. Second, the exact molecular mechanism of apoptotic neuronal death caused by rs2071214 was not investigated. Third, 
this was a hospital-based case control study with relatively small stroke sample sizes.

In conclusion, we observed an association between the development of ischemic stroke in the Korean population and SNP (rs2071214) of survivin gene. This finding may provide evidence that the survivin gene may play a role in the pathophysiology of ischemic stroke and that genetic factor could be responsible for susceptibility to ischemic infarct in Koreans. To the best of our knowledge, this is the first study to indicate the plausibility of an association of a BIRC5 SNP with the development of ischemic stroke. However, additional studies using larger numbers of cases or other populations to determine the exact molecular mechanisms of apoptotic neuronal death caused by rs2071214 in cortical neurons are needed to clarify the biological functions of survivin in ischemic stroke patients.

\section{CONFLICT OF INTEREST}

No potential conflict of interest relevant to this article was reported.

\section{REFERENCES}

1. Hong KS, Bang OY, Kang DW, Yu KH, Bae HJ, Lee JS, et al. Stroke statistics in Korea. Part I: Epidemiology and risk factors: a report from the Korean stroke society and clinical research center for stroke. J Stroke 2013;15:2-20.

2. Grysiewicz RA, Thomas K, Pandey DK. Epidemiology of ischemic and hemorrhagic stroke: incidence, prevalence, mortality, and risk factors. Neurol Clin 2008;26:871-95.

3. Ikram MA, Seshadri S, Bis JC, Fornage M, DeStefano AL, Aulchenko YS, et al. Genomewide association studies of stroke. N Engl J Med 2009;360:1718-28.

4. Lanktree MB, Dichgans M, Hegele RA. Advances in genomic analysis of stroke: what have we learned and where are we headed? Stroke 2010;41:825-32.

5. Somarajan BI, Kalita J, Mittal B, Misra UK. Evaluation of MTHFR C677T polymorphism in ischemic and hemorrhagic stroke patients: a case-control study in a Northern Indian population. J Neurol Sci 2011;304:6770.

6. Gomez-Sanchez JC, Delgado-Esteban M, Rodriguez-
Hernandez I, Sobrino T, Perez de la Ossa N, Reverte S, et al. The human Tp53 Arg72Pro polymorphism explains different functional prognosis in stroke. J Exp Med 2011;208:429-37.

7. Tao HM, Chen GZ, Lu XD, Chen GP, Shao B. TGF- $\beta 1$ 869T/C polymorphism and ischemic stroke: sex difference in Chinese. Can J Neurol Sci 2010;37:803-7.

8. Leu HB, Chung CM, Chuang SY, Bai CH, Chen JR, Chen JW, et al. Genetic variants of connexin37 are associated with carotid intima-medial thickness and future onset of ischemic stroke. Atherosclerosis 2011;214:101-6.

9. Munshi A, Rajeshwar K, Kaul S, Al-Hazzani A, Alshatwi AA, Sai Babu M, et al. Interleukin-10-1082 promoter polymorphism and ischemic stroke risk in a South Indian population. Cytokine 2010;52:221-4.

10. Conway EM, Zwerts F, Van Eygen V, DeVriese A, Nagai $\mathrm{N}$, Luo W, et al. Survivin-dependent angiogenesis in ischemic brain: molecular mechanisms of hypoxiainduced up-regulation. Am J Pathol 2003;163:935-46.

11. Broughton BR, Reutens DC, Sobey CG. Apoptotic mechanisms after cerebral ischemia. Stroke 2009;40: e331-9.

12. Sairanen T, Karjalainen-Lindsberg ML, Paetau A, Ijas $\mathrm{P}$, Lindsberg PJ. Apoptosis dominant in the periinfarct area of human ischaemic stroke: a possible target of antiapoptotic treatments. Brain 2006;129(Pt 1):189-99.

13. Granger CV, Dewis LS, Peters NC, Sherwood CC, Barrett JE. Stroke rehabilitation: analysis of repeated Barthel index measures. Arch Phys Med Rehabil 1979;60: 14-7.

14. Adams HP Jr, Davis PH, Leira EC, Chang KC, Bendixen BH, Clarke WR, et al. Baseline NIH Stroke Scale score strongly predicts outcome after stroke: a report of the Trial of Org 10172 in Acute Stroke Treatment (TOAST). Neurology 1999;53:126-31.

15.Zhu Y, Li Y, Zhu S, Tang R, Liu Y, Li J. Association of surviving polymorphisms with tumor susceptibility: a meta-analysis. PLoS One 2013;8:e74778.

16. Hata J, Kubo M, Kiyohara Y. Genome-wide association study for ischemic stroke based on the Hisayama study. Nihon Eiseigaku Zasshi 2011;66:47-52.

17. Kubo M. Genetic risk factors of ischemic stroke identified by a genome-wide association study. Brain Nerve 2008;60:1339-46.

18. Sun L, Zhang Z, Xu J, Xu G, Liu X. Chromosome 4q25 
variants rs2200733, rs10033464, and rs1906591 contribute to ischemic stroke risk. Mol Neurobiol 2015 Jul 11 [Epub]. http://dx.doi.org/10.1007/s12035-0159332-x.

19. Cao YY, Ma F, Wang Y, Wang DW, Ding H. Rs2200733 and rs10033464 on chromosome 4q25 confer risk of cardioembolic stroke: an updated meta-analysis. Mol Biol Rep 2013;40:5977-85.

20. Doyle KP, Simon RP, Stenzel-Poore MP. Mechanisms of ischemic brain damage. Neuropharmacology 2008;55:310-8.

21. Sugawara T, Fujimura M, Noshita N, Kim GW, Saito A, Hayashi T, et al. Neuronal death/survival signaling pathways in cerebral ischemia. NeuroRx 2004;1:17-25.

22.Zhang SJ, Buchthal B, Lau D, Hayer S, Dick O, Schwaninger $\mathrm{M}$, et al. A signaling cascade of nuclear calcium-CREB-ATF3 activated by synaptic NMDA receptors defines a gene repression module that protects against extrasynaptic NMDA receptor-induced neuronal cell death and ischemic brain damage. J Neurosci 2011;31:4978-90.

23. Li F, Ambrosini G, Chu EY, Plescia J, Tognin S, Marchisio PC, et al. Control of apoptosis and mitotic spindle checkpoint by survivin. Nature 1998;396:580-4.

24. Yamamoto T, Tanigawa N. The role of survivin as a new target of diagnosis and treatment in human cancer. Med Electron Microsc 2001;34:207-12.
25. Han CH, Wei Q, Lu KK, Liu Z, Mills GB, Wang LE. Polymorphisms in the surviving promoter are associated with age of onset of ovarian cancer. Int J Clin Exp Med 2009;2:289-99.

26. Dai J, Jin G, Dong J, Chen Y, Xu L, Hu Z, et al. Prognostic significance of survivin polymorphisms on nonsmall cell lung cancer survival. J Thorac Oncol 2010; 5:1748-54.

27. Delvaeye M, De Vriese A, Zwerts F, Betz I, Moons M, Autiero $\mathrm{M}$, et al. Role of the 2 zebrafish survivin genes in vasculo-angiogenesis, neurogenesis, cardiogenesis and hematopoiesis. BMC Dev Biol 2009;9:25.

28. Li F, Brattain MG. Role of the Survivin gene in pathophysiology. Am J Pathol 2006;169:1-11.

29. Wang H, Holloway MP, Ma L, Cooper ZA, Riolo M, Samkari A, et al. Acetylation directs survivin nuclear localization to repress STAT3 oncogenic activity. J Biol Chem 2010;285:36129-37.

30. Sehara Y, Sawicka K, Hwang JY, Latuszek-Barrantes A, Etgen AM, Zukin RS. Survivin is a transcriptional target of STAT3 critical to estradiol neuroprotection in global ischemia. J Neurosci 2013;33:12364-74.

31. Mallolas J, Rodriguez R, Gubern C, Camos S, Serena J, Castellanos M. A polymorphism in the promoter region of the survivin gene is related to hemorrhagic transformation in patients with acute ischemic stroke. Neuromolecular Med 2014;16:856-61. 